\title{
Management in Education
}

\section{(co)Meta-reflection as a method for the professional development of academic middle leaders in higher education.}

Anthony Thorpe (a) and Diane Garside (b)

(a) School of Education, University of Roehampton, London, UK

Dr Anthony Thorpe * Corresponding author

Senior Lecturer in Leadership and Management

School of Education

University of Roehampton

London

United Kingdom

Email a.thorpe@roehampton.ac.uk

$+44(0) 2083923895$

(b) School of Business, University of Roehampton, London, UK

Diane Garside

Senior Lecturer

School of Business

University of Roehampton

London

United Kingdom

Email: d.garside@roehampton.ac.uk

+44 (0)208392 3015 
(co)Meta-reflection as a method for the professional development of academic middle leaders in higher education.

\section{Abstract}

The professional development of middle leaders in higher education is little considered in existing research though there are general concerns being raised about the suitability of the professional development opportunities currently available. This article develops and explores the use of meta-reflection as a method for professional development, particularly of academics with direct responsibilities for courses and programmes such as course leaders, directors, and co-ordinators. As an extension of reflective practice, (co)meta-reflection is proposed as a joint activity involving two, or more people, seeking to develop their thought and practice by moving from descriptive to analytical levels of reflection. We provide an example of a (co)meta-reflective exercise and identify it as an approach with considerable potential to address the problems that middle leaders face, and call for further exploration of it as a method for professional development.

Key words: higher education, middle leaders, middle managers, reflection, professional development.

\section{Introduction}

The article proposes the use of (co)meta-reflection as a method for, or form of, the professional development of academic middle leaders in higher education focusing on those academics with direct responsibilities for courses and programmes. By this approach to the professional development for academic middle leaders in higher education, we contribute to the literature by first reflecting on the situation, challenges and professional development in a little researched area, and second, by exploring the links between reflection and the development of (co)meta-reflection as a method for professional development. We, the 
authors of this article, are two course leaders from different faculties and disciplines within a university in the United Kingdom (UK) ${ }^{i}$.

The professional development of higher education academics is particularly topical with the perception amongst some practitioners that universities are increasingly preferring 'credentialism for competences already achieved, rather than any kind of voluntary professional development' (Locke et al., 2016: 35) as institutions seek to measure and demonstrate the quality of their learning and teaching as part of the competitive pressures of a marketised environment driven by national and international rankings. These concerns around professional development have been brought into focus in the UK by the development of a professional standards framework for academics (HEA, 2011) and the anticipated introduction of the Teaching Evaluation Framework (BIS, 2016). Whilst academics may have benefited from institutional schemes of accreditation, such schemes may become instrumental tick box exercises rather than genuine opportunities for reflection in a collegial environment (Locke et al., 2016).

We define (co)meta-reflection as a joint activity involving a deeper and more meaningful form of reflection involving two or more people seeking to develop the thought and practice of all participants by moving from descriptive to analytical levels of reflection. Though reflective practice is generally recognised as valuable within the context of nurse and teacher development, we propose the idea of (co)meta-reflection as an extension of reflective practice in professional development that provides the opportunity to jointly reflect on professional experience in order to provide new insights for future practice.

There is no fixed terminology for those academics in UK universities with direct responsibilities for courses and programmes below the level of head of department, for example, the holders of the role are referred to as course leaders or course directors (Bryman, 2007a), programme directors (Bryman, 2007b), or course co-ordinators (Mercer, 
2009). In this article the title course leaders is used. Though we recognise the nuances of any title that appears in the literature, we are not attempting to enter the murky and contested area of the distinctions and cross-overs between the terms in the theory and practice of educational administration ${ }^{\mathrm{ii}}$. The phrase professional development is used rather than management development as, whilst there may be significant areas of overlap, they are not co-terminus in their meaning and the former term is more encompassing of the literature concerned with the development of university academics.

The article reviews the literature about the problems middle leaders in higher education face and their professional development before considering reflection and meta-reflection as forms of professional development. We outline then the thinking behind (co)meta-reflection development through drawing on an exercise which we, the authors, conducted. The exercise is offered as an example of a potential reflective process or dialogic approach, not as a set of empirical findings. The article ends with a discussion of a number of implications that arise and directions for future research.

\section{Middle leaders in Higher Education}

This section reviews the literature about middle leaders in higher education and their professional development. General leadership theory has perhaps limited relevance to academic leadership effectiveness in higher education because aspects of the university context combine 'the need to foster a collegial atmosphere and advancing the department's cause' (Bryman, 2007a: 706) with an understanding of managing autonomy requiring a 'covert' form of leadership practice. Bryman (2007a, 2007b) asks for more research into how to go about consulting staff and maintaining support and commitment in a collegial atmosphere, whilst Floyd (2016) makes a plea for more contributions to the sparse research on supporting academic middle leaders in particular. 
Academic middle leaders are often defined as the level below that of dean or head of faculty such as heads of department and associate deans. Marshall's (2012) ten middle leaders from academic and service departments in New Zealand higher education institutions described themselves as 'caught' between senior leaders and those they saw as their colleagues or peers in their teams, and that, when it comes to resources and academic matters, they are stuck 'between competing imperatives, institutional dynamics and institutional structures' (Marshall, 2012: 504). Mercer also writes of, 'the tensions inherent in any position sandwiched between senior management and shop-floor workers... trying to juggle teaching, research and administration' (Mercer, 2009: 350).

Interviews with Australian higher education middle leaders yielded themes of feeling overwhelmed by the role, having a sense of huge responsibility but with little power, being ever reactive to events, feeling isolated but enjoying making a difference in others' lives and seeing the building of relationships with colleagues as important support structures (Pepper and Giles, 2015). Some UK based middle managers perceived the rewards to be few with manifold barriers (Floyd, 2012). Conflicts between personal and professional identities leading to academic identity schisms emerge from those holding these roles being also 'managed academics' requiring them to balance, manage and switch between multiple identities (Branson et al., 2016; Floyd and Dimmock, 2011; Winter, 2009). This situation can be further complicated by the ambiguity around acceptance of the role of course leader by some holders, as well as the recognition and acknowledgement of their role by people in the surrounding organization structure (Holmes, 2014).

The tensions experienced by middle leaders often emerge around change where some discourses recognise their importance and vital contribution whilst others characterise them as both poor followers and leaders resistant to change due to matters of self-interest, or as just getting in the way of the senior management team's vision (Clegg and McAuley, 2005; Hotho, 2013; Radelli and Sitton-Kent, 2016). The limits of control and agency are often 
missing in these discourses as Bottery (2003) highlights through identifying the problems facing leaders in creating and maintaining learning communities in educational organizations because of a 'low-trust culture of unhappiness'.

Attention has been drawn to the lack of research about the variety of formal roles in university departments, other than that of a head of department, including course leaders (Bryman, 2007a, 2007b; Mercer, 2009; Smith, 2005). With a focus on academics having roles such as course co-ordinators and project leaders below the level of head of department, Mercer (2009) specifically considers their 'untold story' and the impact of new managerialism upon them. She concludes that they face a number of kinds of tensions that department heads do and she calls for more support similar to that needed for heads of department but also for 'informal opportunities for self-reflection, and chances to share their experiences with peers, rather than specific training courses' (Mercer, 2009: 357).

The narrowness of leadership development in many contexts leads to the dominance of training through skills building at the expense of approaches drawing on life experiences (Boerema, 2011) prompting calls for an understanding of the multiple meanings of leadership development to promote a consideration of alternative discourses (Mabey, 2013). Inman (2009) presents a situation in English and Welsh university settings were academic middle leaders acquire what they know from their practice and life experiences as little formal development is being provided for them. She suggests that universities need to promote opportunities for 'collective articulation and sharing of experiences' which draw on this informal learning through, for example, formal mentoring systems and professional learning communities and 'providing guided critical reflection on practice' (Inman, 2009: 431). Griffiths (2009) also speaks of the need to create spaces and supportive environments specifically for women managers in universities to discuss problems. She identifies the use of action sets and coaching or women-only training because of the particular complexities of how gender is embedded in women's everyday practice. 
In the broader context of a continuing professional development programme for university academics in England, Wood and Su (2014) argue that the role of professional dialogue is underplayed and propose the creation of dialogical or 'shared' spaces in which critical perspectives on practice can emerge. The process of 'interthinking' is a sense-making process between peers that aims to enhance professional learning. They illustrate how critically reflective encounters through peer mentoring relationships focusing on pedagogical practice can create 'more democratic understandings about academic practice and reforms in higher education' (Wood and Su, 2014:1).

In summary, the literature identifies the limitations of what is presently offered as professional development to support middle leaders in higher education in addressing the problems and challenges they face. Locke et al. (2016: 5) suggest that academics value 'reflection on material generated in their own practice and an approach which allows integration with career development' indicating the need for more flexible and collegiate forms of reflective practice. There is a need for further research into new and broader methods promoting more activities aimed at supporting peer self-reflection and sharing.

\section{Reflection and meta-reflection as a form of professional development}

We now turn to the consideration of meta-reflection as a possible way to enable forms of professional development which promote sharing experiences and narratives. The use of reflection in teacher and nurse education is well established (Betts, 2005; Hagström and Scheja, 2014; Korkko et al., 2016; Kothagen and Vasalos, 2005; Ottesen, 2007; van Manen, 1995) and its contribution to inter-professional education has been noted (Clark, 2009) as has its potential for supporting self-directed professional growth (Kothagen, 1999). Yet there is a call for a move to something deeper or more fundamental which has been called 'core reflection' or 'meta-reflection' with links to meta-awareness and meta-analysis as both a precondition as well as an outcome of learning (de Freitas and Neumann, 2009; Kothagen and 
Vasalos, 2005). Breaking reflection into stages is seen to support the move from descriptive to analytical levels of reflection, for example, Bengtsson (1995) identifies four basic aspects as reflection as self-reflection, reflection as thinking, reflection as self-understanding and the distancing function of self-reflection; whilst Samuels and Betts (2007) write of the four mechanisms of revisiting reflections, using structure, taking responsibility and metacognition.

Reflection as professional development through using participants' professional case studies has been explored in previous studies, for example, school teachers undertaking masters dissertations used reflective practice to enable them to analyse their development during the research process (Maaranen and Krokfors, 2007). Black and Plowright (2010) deployed a multi-dimensional model of reflection with postgraduate pharmacy students which sought to go beyond simplistic presentations in previous literature and concluded that this approach was transferrable to other professional areas, whilst teachers undertaking action research projects, also in the UK, have used a range of collaborative reflective practices to evaluate and gain a greater understanding of their practice using approaches such as reflective discussions, audio reflections, a paper-based learning and evaluation tool, and an online hub (Bevins et al., 2011).

The use of reflective practice groups in the Australian health service supported managers to develop their management skills with the researcher recommending that such practice should become part of an organization's development strategy (Boucher, 2007). Yet Betts (2004) raises important points to be critical about the use of reflective practice, including asking whose interests are being served through its use and the need to consider more collective forms of the practice, before she ends by noting that though becoming the meta-reflective individual is not an easy state to achieve.

Autoethnography has been used in explorations of situation learning related to leadership practice and academic identity (Kempster and Stewart, 2010; Learmonth and Humphreys, 
2012). As a form of research seeking a greater understanding of cultural experience through description and systematic analysis of personal experience, autoethnography draws on ethnography and also autobiographical writing (Ellis et al., 2010). Its proponents speak of autoethnography as an 'unorthodox approach' providing researchers 'with new forms of empirical material' (Learmonth and Humphreys, 2012: 112). As with meta-reflection, there is a concern with personal experience and the emphasis on self-reflexivity.

\section{A process of (co)meta-reflection.}

The example of (co)meta-reflection described in this section is used to illustrate a potential process or dialogic approach that might contribute to developing more participative and forms of professional development that promote understanding and improvements in practice for academic middle leaders in a university. The example is not presented as the results of a research project but offered as part of this article's tentative exploration into how (co)meta-reflection may work and the benefits the process might bring to the participants.

The stages of the exercise took place over a three month period but we think the time scale could be shortened or lengthened depending upon circumstances. The procedures or steps were multi-dimensional drawing upon Bengstsson (1995) and Bevins et al. (2011) but we are not suggesting these are simple, distinct or necessarily prescriptive stages:

a) Original project reflection (self-reflection- on paper)

b) Purposeful conversation as meta-reflection (reflection as thinking)

c) Reflection on conversation as meta-reflection (reflection as self-understanding)

d) Reflection overall as meta-reflection (reflecting with its distancing function)

We embarked on this exercise after informal conversations, as two course leaders from different faculties within the same UK based university, about the value of shared reflections and how collaboration might develop through new forms of reflective practice in a supportive environment. The first stage (self-reflection on paper) involved one of us preparing a written 
reflection on a recent project that had collected the views of staff and students about enhancing student employability within programmes. We then met to discuss the written reflection (reflection as thinking). A loose conversation schedule was drawn up to support the meta-reflection in the meeting revolving around the dilemmas and how they might be addressed by course leaders.

For the next stage (reflection as self-understanding), we each wrote a reflection on the conversation itself before sharing these writings at a meeting in the final stage (reflection with its distancing function). We discussed and analysed our reflective process by tracing the themes through the various stages of the exercise as well as considering ways forward for our practice. The two themes of fragmentation and coherence which emerged from the conversations are discussed below as an illustration of the process.

Fragmentation: The first stage reflection noted a lack of consensus around approaches to the curriculum as although all the academics were working within the same department, they had quite different ways of thinking about the curriculum. Our first meeting highlighted the difficulties for course leaders trying to accommodate colleagues' perspectives with their different visions of the purpose of a university, different philosophical perspectives, and different lived experiences as well as the many ways they constructed their own identities as teachers, researchers, subject specialists and/or practitioners. What emerged in the subsequent stages was the struggle with the concept of the course leader and how this role meant different things to different people.

The meta-reflective conversations helped to shed more light on the fragmented curriculum development approach. By using synthetic reasoning apportioning appropriate weight to our own lived experiences, we discussed how our expectations are influenced by previous professional experiences in settings outside of universities where collaboration was more evident and expected and autonomy less valued. We reflected on why people might not 
want to work together and the issue of multiple identities for lecturers with many different roles and tasks to perform. Through the (co)meta-reflection process it emerged that there could well be a desire for a less fragmented approach to curriculum development and that forming an academic community of practice might encourage participation.

Coherence: The experiences of seeking coherence but finding fragmentation led to reflective conversations about the expectations incumbent on a course leader to provide a transparent curriculum to students in a context where there is a feeling amongst academics that there are already too many rules and over-formalisation. The conversation enabled further reflection on seeking coherence rather than conformity and not confusing the two. We then explored the level of coherence needed in an environment where argument and difference are highly valued, but policy pressures and calls for accountability exist.

Overall, the (co)meta-reflective exercise identified and placed everyday occurrences of situated course leadership in the wider context. Our practice could be explored in a way that was relevant to both of us as we reflected on how challenges and dilemmas are played out in particular situations. The reflective conversation also allowed us to consider those things we could, and could not, change so identifying implications for future practice. Despite the top-down external factors such as marketisation and the intense competition which are driving the agenda in universities, there remained the possibility that course leaders could still form a community of practice and find a space to define commonly-held values. The reflective process also involved identifying future strategies, for example, that a course leader in a period of scarce resources might find it better to relinquish some autonomy at programme level and negotiate shared definitions of the curriculum with colleagues at a school level rather than continue to embed multiple specialist activities at a programme level in an ad hoc fashion.

\section{Discussion and further research}


The process of (co)meta-reflection seeks to enable reflective conversations about dilemmas arising from professional experiences and may provide the opportunity to draw out issues and implications to enhance professional development. However, further theoretical development and empirical research is needed so this section briefly considers some of the issues around the positioning of (co)meta-reflection as a professional development method and areas for future research.

The caveat that we are not presuming universality of our experience needs restating as our example given above was provided only to illustrate some possibilities for (co)meta-reflection as a professional development tool to create the spaces to share experiences and narratives called for in the literature (Griffiths, 2009; Inman, 2009; Mercer, 2009). How such exercises might play out in other higher education institutions would be important to investigate. Universities should not be assumed to be mono-cultural but, as is often be the case in the UK, they can be multi-cultural and multi-national with cross-cultural needs. Institutions may well be different between and within countries because of aspects of the academic environment such as levels of academic freedom, individual autonomy and governance systems.

Further work on examining the connections and exchanging insights with autoethnography would be welcome in the development of (co)meta-reflection. They both seek to generate insights for practice and share concerns around personal experience, co-operation, and selfreflexivity as well as some of the stages in their practice being similar (Kempster and Stewart, 2010; Learmonth and Humphreys, 2012).

However, autoethnography has positioned itself as an alternative research method challenging universal narratives, whilst (co)meta-reflection emerges from the literature of professional development and reflection so the purposes and ends may overlap at points but they are different in aspects of their theory and practice. A further point of contrast is that 
(co)meta-reflection does not aim to produce a co-authored piece of writing (Kempster and Stewart, 2010). The peer nature of (co)meta-reflection should involve all participants reflecting on their practice as a professional development activity rather than adhering to an autoethnographical positioning of one of the participants as the object of research (Learmonth and Humphreys, 2012: 99). Yet there is something about how (co)metareflection makes professional development a form of inquiry that might appeal to academics in particular and which could be fruitfully explored.

Our exercise indicates that (co)meta-reflection has the potential to be more than simply an outlet for professionals to share their frustrations with the constraints of the role, important as such opportunities are. The reflective discussion helped to locate our agency, as well as those things which restrict us, so the exercise illuminated the situation and identified implications for future practice. Moves towards credentialism and crude measures for professional development raise the concern that reflective practice might be squeezed out of professional development (Locke et al., 2016) but rather than enforcing increasing isolation and individualism in professional development, (co)meta-reflection may offer much greater benefits through collaboration providing a participative way of moving forward that other forums do not.

There is also potential in addressing Griffiths's (2009) call for spaces for women's professional development with the emphasis upon the co-development of the participants to explore the tensions, contradictions and rewards that the women expressed in her study with a view to growing from those experiences and identify ways forward. She identifies the need for 'more women managers and leaders to act as positive role models to others,' (Griffiths 2009: 404) and such modelling could appear in the sharing reflective practice rather than through the status and positioning of the actors within the organizational hierarchy. Though our exercise was different to that of Wood and Su (2014) as it did not have the planned assessed element of their project, we are extending the 'interthinking' and 'peer-enabled 
professional dialogic process' they refer to by not only using face-to-face dialogue but also text and recordings to look both at the context and the inner self.

The next step is to undertake empirical research to develop the (co)meta-reflection approach into a method that others could practise, without being overly prescriptive, and to explore its place within formal and informal professional development literature and practice. There were just two participants in the exercise referred to in this article but could more be involved valuably? Would it make a difference how the need for the (co)meta-reflection had developed and what the intended outcomes were? How might other forms of thought such as strategic and tactical thinking be incorporated into the practice? The inter-disciplinary and departmental collaborative opportunities offered by (co)meta-reflection should also be investigated. It could be used to form a community of practice, as it involves peer reflection rather than line management appraisal, giving richness to the experience especially where participants are from different backgrounds and disciplines.

\section{Conclusion}

We have proposed the idea of (co)meta-reflection as a method for, or form of, professional development in a university setting. As a joint endeavour involving a deeper and more meaningful form of reflection involving two, or more people, (co)meta-reflection seeks to develop thought and practice by moving from descriptive to more analytical levels of reflection in a suitably informal way whist remaining purposeful and focused. It is an extension of reflective practice which offers the opportunity for participants to jointly reflect on professional experience to provide new insights which could address their professional problems and challenges.

The call for (co)meta-reflection is linked to the wish to develop more group and participative forms of professional development for middle leaders in higher education which promote 
deeper understanding and improvements in practice. Though deeper levels of reflection enhance one's ability to examine issues, it does not necessarily imply that developmental changes occur. However, (co)meta-reflection may be helpful in recognising reflection's multidimensional aspects through drawing on a wider range of practices. As a method for professional development, (co)meta-reflection may have considerable potential but further theoretical exploration and empirical research is required.

\section{References}

Bengtsson $\mathrm{J}(1995)$ What is Reflection? On reflection in the teaching profession and teacher education. Teachers and Teaching 1(1): 23-32.

Betts J (2004) Theology, therapy or picket line? What's the 'good' of reflective practice in management education? Reflective Practice: International and Multidisciplinary Perspectives 5(2): 239-251.

Bevins S, Jordan J and Perry E (2011) Reflecting on professional development. Educational Action Research 19(3): 399-411.

BIS (2016) Success as a knowledge economy: teaching excellence, social mobility and student choice. Department for Business Innovation and Skills. Available at: https://www.gov.uk/government/publications/higher-education-success-as-aknowledge-economy-white-paper (accessed19 August 2016).

Black PE and Plowright D (2010) A multi-dimensional model of reflective learning for professional development. Reflective Practice: International and Multidisciplinary Perspectives 11(2): 245-258.

Boerema A (2011) Challenging and Supporting New Leader Development. Educational Management Administration and Leadership 39(5): 554-567.

Bottery M (2003) The Leadership of Learning Communities in a Culture of Unhappiness. School Leadership and Management: Formerly School Organisation 23(2): 187-207.

Boucher C (2007) Using reflective practice as a management development tool in a Victorian Health Service. Reflective Practice: International and Multidisciplinary Perspectives 8(2): 227-240.

Branson CM, Franken M and Penney D (2016) Middle leadership in higher education: A relational analysis. Educational Management, Administration \& Leadership 44(1): $128-145$.

Bryman A (2007a) Effective leadership in higher education: A literature review. Studies in Higher Education 32(6): 693-710. 
Bryman A (2007b) Effective leadership in higher education. LFHE summary report. London: Leadership Foundation for Higher Education.

Bush T (2008) From management to leadership: semantic or meaningful change?

Educational Management, Administration \& Leadership 36(2): 271-288.

Clark PG (2009) Reflecting on reflection in interprofessional education: Implications for theory and practice. Journal of Interprofessional Care 23(3): 213-223.

Clegg S and McAuley J (2005) Conceptualising Middle Management in Higher Education: A multifaceted discourse. Journal of Higher Education Policy and Management 27(1): 19-34.

de Freitas S and Neumann T (2009) The use of 'exploratory learning' for supporting immersive learning in virtual environments. Computers and Education 52(2): 343352.

Ellis C, Adams TE and Bochner, AP (2010) Autoethnography: An Overview. Forum Qualitative Sozialforschung / Forum: Qualitative Social Research 12 (1): article 10. Available at: http://nbn-resolving.de/urn:nbn:de:0114-fqs1101108 (accessed 9 December 2016).

Floyd A (2012) Turning points: the personal and professional circumstances that lead academics to become middle managers. Educational Management, Administration and Leadership 40(2): 272-284.

Floyd A (2016) Supporting Academic Middle Managers in Higher Education: Do We Care? Higher Education Policy 29(2): 167-183.

Floyd A and Dimmock C (2011) 'Jugglers', 'copers' and 'strugglers': Academics' perceptions of being a HoD in a post-1992 UK university and how it influences their future careers. Journal of Higher Education Policy and Management 33(4): 387-399.

Griffiths V (2009) Women Managers in Higher Education: Experiences from the UK. International Journal Of Learning 16(10): 397-405.

Gunter HM (2004) Label and labelling in the field of educational leadership. Discourse 25(1): 21-42.

Hagström L and Scheja M (2014) Using meta-reflection to improve learning and throughput: redesigning assessment procedures in a political science course on power. Assessment \& Evaluation in Higher Education 39(2): 242-252.

HEA (2011) The UK Professional Standards Framework for teaching and supporting learning in higher education. York: Higher Education Academy. Available at: http://www.heacademy.ac.uk/ukpsf (accessed19 August 2016).

Holmes L (2014) Becoming a Leader in Higher Education: An Identity Trajectory Perspective. Final report of a Leadership Foundation for Higher Education Small Development Project. 
Hotho S (2013) Higher Education Change and Its Managers: Alternative Constructions. Education Management, Administration and Leadership 41(3): 352-371.

Inman M (2009) Learning to lead: development for middle-level leaders in higher education in England and Wales. Professional Development in Education 35(3): 417-432.

Kempster S and Stewart J (2010) Becoming a leader: A co-produced autoethnographic exploration of situated learning of leadership practice. Management Learning 41(2): 205-219.

Korkko M, Kyro-Ammala O and Turunen T (2016) Professional development through reflection in teacher education. Teaching and Teacher Education 55(1): 198-206.

Korthagen FAJ (1999) Linking Reflection and Technical Competence: The logbook as an instrument in teacher education. European Journal of Teacher Education 22(2-3): 191-207.

Korthagen $\mathrm{F}$ and Vasalos A (2005) Levels in reflection: Core reflection as a means to enhance professional growth. Teachers and Teaching 11(1): 47-71.

Learmonth M and Humphreys M (2012) Autoethnography and academic identity: glimpsing business school doppelgangers. Organization 19(1): 99-117.

Locke W, Whitchurch C and Smith, H (2016) Shifting landscapes Meeting the staff development needs of the changing academic workforce. Higher Education Academy. Available at: https://www.heacademy.ac.uk/sites/default/files/shifting_landscapes.pdf (accessed 19 August 2016).

Maaranen K and Krokfors L (2007) Time to think? Primary school teacher students reflecting on their MA thesis research processes. Reflective Practice: International and Multidisciplinary Perspectives 8(3): 359-373.

Mabey C (2013) Leadership Development in Organizations: Multiple Discourses and Diverse Practice. International Journal of Management Reviews 15(4): 359-380.

Marshall SG (2012) Educational middle change leadership in New Zealand: The meat in the sandwich. International Journal of Educational Management 26(6): 502-528.

Mercer J (2009) Junior academic-manager in higher education: An untold story? International Journal of Educational Management 23(4): 348-359.

O'Reilly D and Reed M. (2010) 'Leaderism': an evolution of managerialism in UK public service reform. Public Administration 88(4): 960-978.

Ottesen E (2007) Reflection in teacher education. Reflective Practice: International and Multidisciplinary Perspectives 8(1): 31-46.

Pepper C and Giles W (2015) Leading in middle management in higher education. Management in Education 39(2): 46-52. 
Radaelli G and Sitton-Kent L (2016) Middle Managers and the Translation of New Ideas in Organizations: A Review of Micro-practices and Contingencies. International Journal of Management Reviews 18(3): 311-332.

Samuels M and Betts J (2007) Crossing the threshold from description to deconstruction and reconstruction: Using self-assessment to deepen reflection. Reflective Practice: International and Multidisciplinary Perspectives 8(2): 269-283.

Smith R (2005) Departmental leadership and management in chartered and statutory universities. Educational Management, Administration and Leadership 33(4): 449464.

van Manen M (1995) On the Epistemology of Reflective Practice. Teachers and Teaching 1(1): 33-50.

Wenger E (1998) Communities of Practice: Learning, meaning and identity. Cambridge: Cambridge University Press.

Winter R (2009) Academic manager or managed academic? Academic identity schisms in higher education. Journal of Higher Education Policy and Management 31(2): 121131.

Wood M and Su F (2014) A mission possible: Towards a shared dialogic space for professional learning in UK higher education. European Journal of Higher Education 4(4): 363-372.

\footnotetext{
' Universities and other higher education institutions differ between, and within, countries in relation to many aspects of the academic environment such as levels of academic freedom, individual autonomy and governance systems. We, the authors, are working within the context of a university in the UK, and specifically in England, and do not assume a universal context or even a common environment for institutions within the UK.
}

\footnotetext{
ii Marshall (2010) provides a helpful discussion about the conundrum of defining the terms leadership and leader including a critique of the leadership/management discourse that sharply differentiates leadership from, and/or presents it as the antithesis of, management. Other writers have identified the nuanced and often politicised movement from the term administration to management and then to leadership in education and public service settings (Bush, 2008; Gunter, 2004; O’Reilly and Read, 2010). The term 'leader' may just be a synonym for post holders within the hierarchy of an organization with middle leaders
} 
holding posts judged to be below that of the senior rank (Marshall, 2010). Within the confines of this article therefore, we note that a range of titles are used in UK universities for roles with direct responsibilities for courses and programmes, including that of 'course leader' which we are familiar with. Yet these titles may well be different, or not have any equivalent, in other settings and countries. 